\title{
Suicidal behaviour and clinical correlates in young adults in Rwanda: a population-based, cross-sectional study
}

\author{
Joseph Muwonge ${ }^{1}$, Aline Umubyeyi ${ }^{2}$, Lawrence Rugema ${ }^{3}$, Gunilla Krantz \\ 1 Department of Public Health and Community Medicine (Sahlgrenska Academy) University of Gothenburg, Gothenburg, Sweden, ${ }^{2}$ Department of \\ Epidemiology and Biostatistics, School of Public Health, College of Medicine and Health Sciences, University of Rwanda, Kigali, Rwanda, ${ }^{3}$ Department \\ of Community Health, School of Public Health, College of Medicine and Health Sciences, University of Rwanda, Kigali, Rwanda \\ Keywords: rwanda, young adults, clinical correlates, suicidal behaviour \\ https://doi.org/10.29392/joghr.3.e2019080
}

Journal of Global Health Reports

Vol. 3, 2019

\begin{abstract}
Background
A significant proportion of persons who were contemplating suicide or completed suicide had met with a health care provider in the preceding months, however suicidal behaviour was not detected. To improve identification of persons with suicidal behaviour in need of care and support, this study aimed to investigate clinical symptoms that may identify young men and women (aged 20-35 years) with suicidal behaviour (ideation, plan and attempts) in Rwanda.
\end{abstract}

\section{Methods}

This was a secondary analysis of data collected from a population based, cross-sectional study conducted in the Southern province of Rwanda in 2011/2012. After a response rate of $99.8 \%$, the final sample was 917 people (477 women and 440 men). A validated "Mini-International Neuropsychiatric Interview" tool was used to measure suicidal behaviour. Bivariable and multivariable logistic regressions were performed to test the association between suicidal behaviour and clinical symptoms such as major depressive episode, physical pain symptoms and perceived overall health.

\section{Results \\ Approximately, $4.7 \%$ of the number of women $(\mathrm{n}=477)$ and $1.4 \%$ of the number of men $(n=440)$ had attempted suicide in the preceding one month. For women, major depressive episode (Adjusted Odds Ratio, AOR=6.11; 95\% confidence interval CI=4.03-10.84), physical pain symptoms experienced almost daily $(\mathrm{AOR}=1.80 ; 1.15-2.84)$ and poorly perceived overall health $(\mathrm{AOR}=3.08 ; 1.89-5.00)$ were statistically significant correlates of suicidal behaviour. For men, only major depressive episode was a statistically significant correlate of suicidal behaviour (AOR=4.75; 1.72-13.12).}

\section{Conclusion}

At health centre level, trained professionals should be made aware that young adults suffering from depression may also suffer from suicidal behaviour. It is therefore important to sensitively inquire about suicidal behaviour followed by appropriate support. For women in particular, suffering from persistent physical pain symptoms or poorly perceived overall health are warning signs that may indicate suicidal behaviour. At community level, community health workers can use the self-rated health form to identify people in poor health and escort them to the health centre for assessment.

Suicide globally causes about 800,000 deaths a year, of which the majority (78\%) occur in low-and middle-income countries (LMICs). ${ }^{1}$ It is the second leading cause of death among the younger population, aged 15-29 years. $^{2}$ In Rwanda, suicide causes about 12 deaths per 100,000 persons per year (age-adjusted rate), of which the ratio of men to women is $3: 1 .^{3}$ However, the burden of suicide stretches beyond these numbers, with societal and psychological consequences especially affecting the close family and friends. ${ }^{2}$
Besides, for every single completed suicide there are about 20 suicide attempts, ${ }^{4}$ implying that many more people have suicidal thoughts (ideation) or make a suicide plan. Non-fatal suicidal behaviour (henceforth used to refer to ideation, plan, and attempt) is often characterized by psychological distress, anxiety, depression, somatization, and injury 5,6 (indicators of poor quality of life ${ }^{7}$ ).

Suicide prevention is linked to the 'Sustainable Development Goal' (SDG) 3, target 4 "to reduce by one third pre- 
mature mortality from non-communicable diseases through prevention and treatment and promote mental health and well-being by $2030^{\prime \prime} .{ }^{8}$ Under this target, countries should reduce suicide mortality (indicator 3.4 .2$)^{8}$ partly through the creation of responsive health systems for early detection and management of mental illnesses, including suicidal behaviour. ${ }^{9}$ This is especially crucial in Rwanda, where in addition to limited resources for mental health care, persons with mental illnesses still experience stigma and therefore may not actively seek help. ${ }^{10}$ The WHO estimates that approximately $25-50 \%$ of women (estimate only available for women) experiencing suicidal ideation had interfaced with a health care provider in the past four weeks, however suicidal behaviour was not detected. ${ }^{2}$ In addition, previous research highlights that most suicides occur within one month of a hospital visit. ${ }^{11,12}$ Therefore, this presents an opportunity for health care staff to identify and offer help to persons with or at risk of suicidal behaviour. Clinical conditions, such as major depressive episode (MDE), anxiety, and recurrent physical pain (low back pain and headache), are recognized causes of years lived with disability (YLD) in this population ${ }^{13}$ and may signal serious conditions, such as suicidal behaviour. ${ }^{6}$

In Rwanda, mental health care is offered within the national health system at health centres, district hospitals and referral hospitals. ${ }^{14,15}$ The few highly trained mental health nurses, are available at district hospitals, and the psychiatrists, are available at referral hospitals. ${ }^{14,15} \mathrm{~A}$ crucial part of mental health care is therefore provided by general practice nurses, at health centres and community health workers in the villages. ${ }^{14,15}$ Community health workers available in each village, guide and refer patients and their families to the health centres, while general practice nurses identify and treat persons with common mental disorders. ${ }^{15}$ Therefore, suicide prevention programs could tap into this organized system between community health workers and health centres.

Evidence on clinical symptoms associated with suicidal behaviour provides knowledge that can be used to train general practice nurses and community health workers to actively identify persons with or at risk of suicidal behaviour ${ }^{16}$ who would otherwise not ask for help. ${ }^{17}$ An estimate of the number of young people with suicidal behaviour provides a basis for health care service planners to budget and plan for how to take care of these vulnerable people. Yet few studies exist on suicidal behaviour and its clinical correlates in Rwanda.

The primary aim of this study was to investigate clinical symptoms that may identify young men and women with suicidal behaviour and the secondary aim was to estimate the prevalence of suicidal behaviour (ideation, plan and attempts) among young adults, aged 20-35 years in Rwanda. The clinical symptoms under study are major depressive episode, self-reported physical pain symptoms and perceived overall health. This study utilized data from a larger project, the Rwandan Violence, Mental Health and Barriers to Care project (RwVMHBC-project) conducted in 2011/2012.

\section{METHODS}

\section{STUDY DESIGN, SETTING, AND SAMPLE SIZE}

This is a secondary analysis of data from a cross-sectional, population-based study that was conducted in a representative sample of young adults aged 20 to 35 years living in the Southern province of Rwanda. A detailed methodology is already presented in earlier articles. ${ }^{18,19}$

Rwanda has a total population of approximately 12.3 million people $\mathrm{e}^{20}$ with about half the number aged below 20 years, and about $27 \%$ of the total population are aged $20-35$ years. ${ }^{21}$ At the time of the Genocide against the Tutsi in $1994,{ }^{22}$ the current study population was between $3-18$ years of age, as the data collection was performed in 2011/ 2012. The population in this study was young in 1994, they may have suffered from several adverse childhood experiences, for instance separation from parents, displacement, and interpersonal and community violence. ${ }^{22}$

Mental health was one of the main outcome variables of the original project, therefore, the prevalence of depression in women in Rwanda was estimated as $20 \%$ in a previous study, ${ }^{23}$ a power of $80 \%$ and an effect size of 1.5 were used to calculate the sample size to 815 persons. ${ }^{18,19}$ Considering non-responders and a generally lower prevalence of depression in men compared to women, it was decided to increase the sample size to at least 900 , and finally 917 people participated. ${ }^{18,19}$

A multistage sampling approach was used to select participants from the total number of villages in the Southern province. A list of all the villages was provided by the National Institute of Statistics Rwanda (NISR). First, 35 villages (1\%) were randomly selected using Epi Info statistical software from a list of all the 3,512 villages in 8 districts, ensuring that the selected number of villages was proportionate to the total number of villages per district. Second, the number of households was selected proportionate to the number of households in each selected village. Third, in the case of more than one eligible person in the household, only one person was randomly selected using a simple lottery procedure. ${ }^{18,19}$

\section{DATA COLLECTION PROCEDURES}

A team of 13 clinical psychologists from the University of Rwanda, with data collection experience, were trained for two days and a pretesting exercise with a translated questionnaire from English to Kinyarwanda was done and a few revisions were made. ${ }^{18,19}$

In each village, the first participant was selected from a household closest to the centre of the village, identified with help of the village chairperson. Due to the sensitive nature of the research, interviews were conducted in strict privacy, and only one participant per household was interviewed. ${ }^{18,19}$ In addition, interviews were sex sensitive that is, men were interviewed by male interviewers and women by female interviewers to ensure that participants were as comfortable as possible when answering questions. In cases where there was no eligible participant, the nearest household was visited assuming that the two households would experience similar life circumstances. Finally, after a re- 
sponse rate of $99.8 \%$, the sample consisted of 917 individuals (440 men and 477 women) aged $20-35$ years. ${ }^{18,19}$

The whole data collection and entry process was done by trained research assistants but with close supervision from two principal investigators based at the School of Public Health at the University of Rwanda (AU and LR, co-authors of this paper). ${ }^{18,19}$

\section{QUESTIONNAIRE USED}

The researchers in the original project compiled a questionnaire by use of previously validated instruments. It contained items on sociodemographic and psychosocial factors, mental health problems and barriers to care, intimate partner violence and traumatic experiences during the genocide, translated into Kinyarwanda. The validated instruments used were the following: The Mini-International Neuropsychiatric Interview (M.I.N.I) V.6.0.0. tool (reproduced with the authorization of the copyright holder: copyright 1994-2010 Sheenan DV \& Lecrubier Y) module A was used to assess major depressive episode (MDE) ${ }^{24}$ and module $B$ to assess current suicidal behaviour. ${ }^{25}$ The diagnostic criteria used in this instrument is based on the Diagnostic and Statistical Manual of Mental Disorders IV (DSM IV)), AxisI-disorders and International Classification of Diseases 10 (ICD 10). ${ }^{24}$ The developers of the M.I.N.I instrument recommend its use in epidemiological research settings since it does not require clinicians to administer and takes a short time to use. ${ }^{24}$

Items from the Rwanda Demographic Health Survey (RDHS) 2010 questionnaires ${ }^{26}$ were added to assess the sociodemographic and psychosocial variables.

\section{VARIABLES}

\section{DEPENDENT VARIABLE}

\section{SUICIDAL BEHAVIOUR/ SUICIDALITY}

Current suicidal behaviour was assessed by asking respondents five questions on suicide ideation, plan and attempt, that is, "In the past month did you: Think that you would be better off dead or wish you were dead; Want to harm yourself; Think about suicide; Have a suicide plan; Attempt suicide;" and one more question on lifetime suicide attempt namely, "Did you ever make a suicide attempt?"

If a 'yes' response was given to one or more questions, the respondent met the criteria of suicidal behaviour. This was dichotomized as those 'with suicidal behaviour' and those 'without suicidal behaviour'.

\section{INDEPENDENT VARIABLES}

\section{DEPRESSION}

Current major depressive episode (MDE) was assessed by asking respondents if they had experienced seven depressive mood symptoms in the past two weeks preceding the survey. A person met the diagnostic criteria for MDE if they responded yes to three or more of the seven symptoms asked about. This was dichotomised into those 'with MDE' and those 'without MDE' as the reference category.
SELF-REPORTED PHYSICAL PAIN SYMPTOMS (PHYSICAL PAIN).

Physical symptoms were assessed by asking if and how often the respondent suffered from common symptoms namely, headache, chest pain, low back pain, pain in joints and stomach pain. The time frames were 'almost daily', 'weekly', and 'almost never/never'. Suffering from a symptom almost daily was deemed to be of clinical importance. Therefore, the physical pain variable was dichotomized into at least one of the five symptoms experienced almost daily and symptoms experienced weekly and almost never/never as the reference category.

\section{PERCEIVED OVERALL HEALTH (SELF-RATED HEALTH)}

A single question, "would you say your overall health is Excellent, Good, Moderate, Poor or Very poor?" was used to measure the subjective assessment of overall health. This is a validated question and takes approximately one minute to collect and does not require an expert to administer. ${ }^{16}$ This was then dichotomized into 'Good' (excellent/good/moderate) and 'Poor' (poor/very poor) as has been a common practice, ${ }^{16}$ with 'Good' as the reference category.

\section{SOCIODEMOGRAPHIC AND PSYCHOSOCIAL VARIABLES}

Age was measured as a continuous variable and mean values calculated for men and women. Marital status was dichotomized into 'married/cohabiting' and 'not married'. Household size (number of persons living in the household) was measured as a continuous variable. Educational level was categorized into 'secondary school/university level', 'complete primary school/vocational training', and 'incomplete primary school/no schooling’. Employment status was categorized into 'employed with income' (fulltime, irregular, or seasonal work) and 'not employed'. Assets in the household such as a radio, television, refrigerator, bicycle, motorcycle, car, mobile phone and computer was assessed to ascertain the living standard of the household. This was categorized into 'improved household' (owning at least one of the assets) or 'poor household' (none of the assets). The variable was then used as a proxy for socio-economic status as done in demographic health surveys. ${ }^{26}$ Perceived social support was assessed by asking how often the respondent would count on a close friend or family member to offer support in case they ever needed it, classified into 'instrumental support' (food, housing, and money), 'informational support' (guidance), and 'emotional support' (support when with personal problems) with dichotomy outputs i.e. 'Good (Always/ often)' or 'Poor' (Sometimes/Never). Partner's characteristics were also assessed and categorized, that is, partner's educational level as 'completed primary school or higher' and "incomplete primary school/no schooling" and partner's employment status as 'employed' or 'not employed'.

\section{STATISTICAL ANALYSIS}

The dataset had negligible missing data ${ }^{27}$ and was therefore handled by available case analysis ${ }^{28}$ using the IBM Statistical Package for the Social Sciences (SPSS) version 25.0 (IBM Inc, Armonk, NY, USA). All data was sex-disaggregated.

Descriptive statistics were performed and presented in frequency tables, and graphs to give a summary and distri- 
bution of key variables in the data. Statistically significant differences in men and women were tested and displayed based on Pearson Chi-Square test and Fisher's Exact Test $(P$-values displayed).

Bivariable and multivariable logistic regressions were finally performed using the enter method (SPSS's standard regression analysis) to test the association between independent variables and the categorical dependent variable, suicidal behaviour. The clinical factors that showed statistical significance with suicidal behaviour in the bivariable analyses were used in the multivariable logistic regression analyses as independent variables. Statistically significant sociodemographic and psychosocial variables were controlled for. Age, and household assets as a proxy for socioeconomic status were added for theoretical reasons as they have been shown to be associated with suicidal behaviour in other studies. ${ }^{6,29}$ Crude and adjusted odds ratios and 95\% Confidence Intervals were calculated.

\section{ETHICAL CONSIDERATIONS}

Ethical clearance was sought and granted by the Rwanda National Ethics Committee, reference number FWA Assurance No. 00001973, IRB 00001497 of IORG0001100. Informed consent (verbal and written) by the participants was sought following the provision of an introduction to the research. Any risk for harm, confidentiality and complete anonymity assurance and participation rights were communicated to the participants orally and in writing. ${ }^{18,19}$ There were no financial benefits for participating in the research. However, interviewers were tasked to refer participants who requested support to the nearest health facility. ${ }^{18,19}$

\section{RESULTS}

\section{RESPONDENTS’ CHARACTERISTICS}

A total sample of 917 persons comprising 440 men with a mean age of 27.3 years, and 477 women with a mean age of 28.0 years participated in this study. This sample had an average household size of 4.3 persons, and the majority, 578 (63\%) were either married or cohabiting. A large proportion (64\% men and $70 \%$ women) had not completed primary school or had never been to school and had not been employed with income in the past 12 months (80\% men and $90 \%$ women). Close to one third (29\%) of the respondents were from poor households measured as having none of the selected assets in the household (Table 1).

\section{SUICIDAL BEHAVIOUR (CURRENT)}

Suicidal behaviour was common in this sample, with rates higher in women compared to men $(P$ values $<0.05)$ (Table $1)$. The prevalence of suicidal ideation was more than two times higher in women (21\%) compared to men (8\%). Similarly, more women than men had devised a suicide plan $(7 \%$ women, $1.8 \%$ men) and attempted suicide (4.7\% women, $1.4 \%$ men) in the month preceding the survey (Figure 1).

\section{CLINICAL FACTORS}

Clinical factors of interest, major depression, physical pain symptoms and poorly perceived overall health were more prevalent in women as compared to men $(P$ values $<0.05)$ (Table 2). As shown in Table 2, 26.5\% of the number of women and $12 \%$ of the number of men met the diagnostic criteria for current major depressive episode (MDE). A larger proportion of women compared to men reported experiencing two or more physical pain symptoms almost daily that is, two symptoms $(12.2 \%$ vs $0.9 \%)$ and three or more symptoms (14.1\% vs $1.4 \%$ ). A significant proportion of women (34.6\%) and men (25.7\%) rated their overall health as “poor” or "very poor” (Table 2).

\section{ASSOCIATIONS BETWEEN CLINICAL FACTORS AND SUICIDAL BEHAVIOUR}

For women, suffering from MDE (OR=6.70; 4.17-10.76), experiencing physical pain almost daily $(\mathrm{OR}=1.76 ; 1.13-2.73)$ and/or rating their overall health as poor/very poor $(\mathrm{OR}=2.98 ; 1.90-4.65)$ were all associated with increased odds of suicidal behaviour in the bivariable models (Table $\underline{3}$ ). In the multivariable analyses (adjusting for age, marital status, poverty and emotional social support), MDE, physical pain and poorly perceived overall health maintained statistical significance with suicidal behaviour in women (Table 3).

For men, only major depression $(\mathrm{OR}=6.80 ; 3.36-13.76)$ was a statistically significant correlate of suicidal behaviour in the bivariable model (Table 4). Suffering from MDE was still a statistically significant correlate of suicidal behaviour in the adjusted model (adjusting for age, poverty and employment status of partner), maintaining a more than fourfold increase in odds for suicidal behaviour compared to men without MDE (Table 4).

\section{OTHER FACTORS}

Poor emotional social support was significantly associated with suicidal behavior in women $(\mathrm{OR}=1.72$; 95\% CI=1.05-2.81) (Table 3).

\section{DISCUSSION}

This study provides important evidence on suicidal behaviour (ideation, plan, and/or attempt) and associated clinical factors in young men and women aged 20-35 years living in the Southern province of Rwanda. About two in ten of the women and one in ten of the men met the criteria for suicidal behaviour. For women, major depressive episode (MDE), physical pain experienced almost daily, and poorly perceived overall health were statistically significant correlates of suicidal behaviour. In addition, these women were also more likely to report poor emotional support. For men, suffering from MDE was the only statistically significant correlate of suicidal behaviour. 


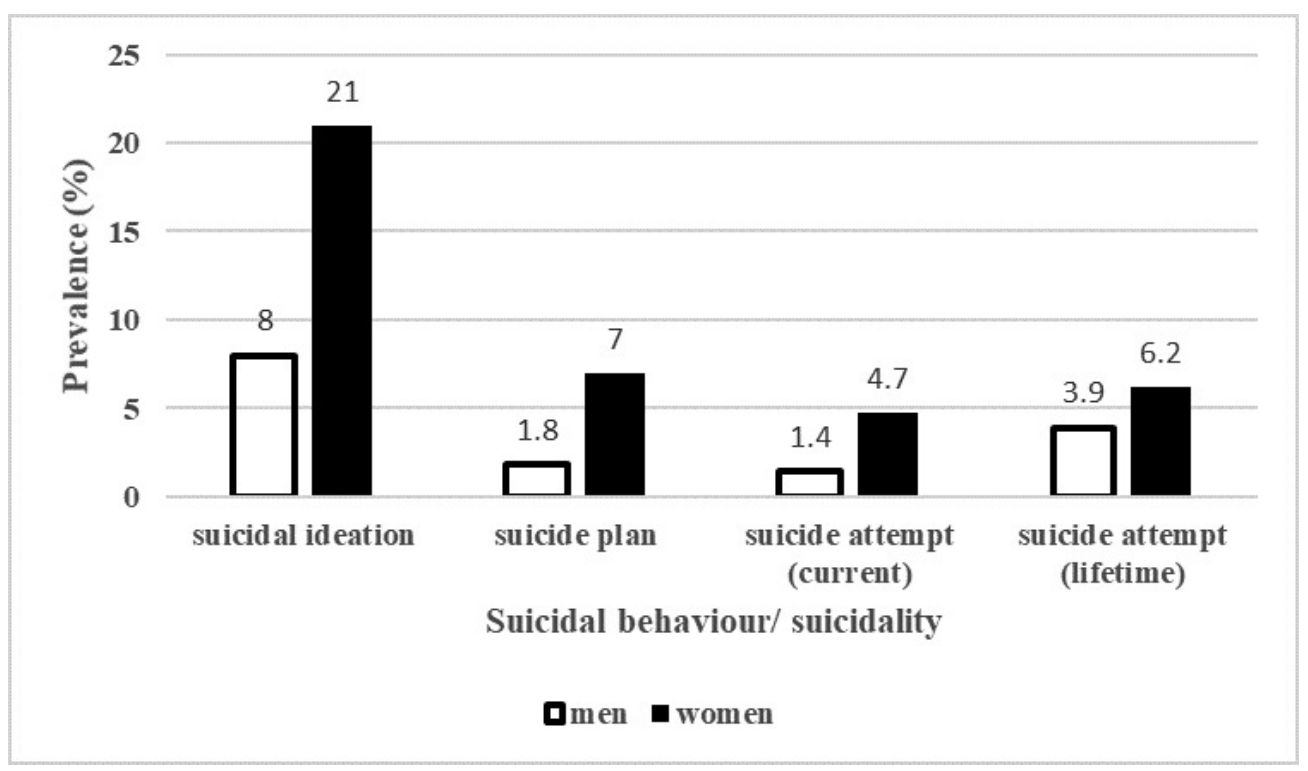

Figure 1. Bar graph showing the prevalence of suicidal behaviour in the sample (n=438 men and 477 women).

\section{CLINICAL-RELATED CORRELATES OF SUICIDAL BEHAVIOUR}

Depression is a known risk factor of suicide ${ }^{30}$ and was highly prevalent in the studied population. Young men and women with current major depressive episode (MDE) were also more likely to report suicidal behaviour that is, an adjusted four and six-fold increase in odds respectively, of suicidal behaviour compared to those not suffering from MDE. This was similar to findings in the USA ${ }^{31}$ and Nigeria. ${ }^{6}$ The association between MDE and suicidal behaviour may be explained by the presence of sadness, feelings of being unworthy, lost interest in life among other depressive mood symptoms. ${ }^{1}$ According to Joiner's Interpersonal-Psychological theory of suicidal behaviour ${ }^{32}$ a person with MDE may feel burdensome or alienated and not valuable to their social network and hence may start to perceive death as better than staying alive. ${ }^{32}$ The 2016 global burden of diseases (GBD) study, ranked depressive disorder as the fourth biggest cause of years lived with disability (YLD) in Rwanda. ${ }^{13}$ Therefore, its management is crucial for both improvement of quality of life and prevention of suicidal behaviour.

Physical pain experienced almost daily was a statistically significant correlate of suicidal behaviour in women but not in men. In comparison, a study among HIV patients in Uganda, reported that physical pain was a statistically significant correlate of suicidality (suicidal behaviour) only in the bivariable analysis. ${ }^{33}$ The correlation of physical pain and suicidal behaviour may differ by type, intensity, and duration of pain. ${ }^{34}$ However, this was beyond the scope of our study. Overall, physical pain symptoms were highly prevalent in our sample and this was in agreement with the GBD 2016 study which ranked physical pain symptoms such as low back pain and headache among the leading causes of YLD in Rwanda. ${ }^{13}$ Physical pain symptoms in this population may be an expression of psychological problems (somatization) and/ or stressful life situations such as exposure to intimate partner violence (IPV) ${ }^{35,36}$ which is highly prevalent among women in Rwanda. 37

Poorly perceived overall health was a statistically significant correlate of suicidal behaviour in women but not in men. We found that women who perceived their overall health as poor or very poor were approximately three times more likely to report suicidal behaviour than those who perceived their overall health as moderate, good, or excellent. Similarly, a study in the USA reported that persons who perceived their overall health as poor had twice the odds of suicidal ideation and attempts. ${ }^{38}$ Although it is not clear what constitutes poorly perceived overall health in this population, a qualitative study in the USA reported that some respondents focused on underlying health problems (physical and mental), negative health behaviour, and/or poor physical condition (fitness). ${ }^{39}$ The concept of perceived overall health has been criticized for being abstract and not specific enough to pinpoint the underlying problem. ${ }^{39}$ However, perceived overall health is an important indicator of quality of life and can be used to identify vulnerable people at population level. ${ }^{16}$ This is particularly important in contexts with low mental health literacy and poor help seeking behaviour for mental illnesses. ${ }^{17}$ Our study adds to the initial evidence from two studies in the USA, 38,40 that poorly perceived overall health is a correlate of suicidal behaviour in women.

\section{PREVALENCE OF SUICIDAL BEHAVIOUR}

To provide an estimation of the number of young adults who may need help, we report prevalence rates for suicidal ideation, plans and attempts. The past one-month prevalence of suicidal behaviour was relatively high in this population, with rates more than twice as high in women as in men across all suicidal behaviour domains (ideation, plans and attempts). Specifically, many more women than men had thought about suicide (21\% versus $8 \%$ ), devised a suicide plan (7\% versus $1.8 \%$ ) and attempted suicide $(4.7 \%$ 
Table 1. Descriptive statistics of sociodemographic and psychosocial factors classified by sex*

\begin{tabular}{|c|c|c|c|c|c|}
\hline \multicolumn{2}{|c|}{ Sociodemographic and economic factors: } & \multirow{2}{*}{$\frac{\text { Total (N=917), n (\%) }}{578(63.4)}$} & \multirow{2}{*}{$\frac{\text { Men }(\mathrm{N}=440), \mathrm{n}(\%)}{236(53.8)}$} & \multirow{2}{*}{$\frac{\text { Women (N=477), n (\%) }}{342(72.3)}$} & \multirow{2}{*}{$\frac{P \text { value }}{.000}$} \\
\hline Marital status ( $n=912)$ & Married/Cohabiting. & & & & \\
\hline 位 & Not married & $334(36.6)$ & $203(46.2)$ & $131(27.7)$ & \\
\hline \multirow{2}{*}{ Employment status (n=913) } & Employed & $134(14.7)$ & $88(20.2)$ & $46(9.6)$ & .000 \\
\hline & Not Employed & $779(85.3)$ & $348(79.8)$ & $431(90.4)$ & \\
\hline \multirow{3}{*}{ Educational level $(n=904)$} & Secondary school/University level & $117(12.9)$ & $50(11.5)$ & $67(14.2)$ & .004 \\
\hline & Complete primary school/Vocational training & $178(19.7)$ & $105(24.2)$ & $73(15.5)$ & \\
\hline & Incomplete primary school/No schooling & $609(67.4)$ & $278(64.2)$ & $331(70.3)$ & \\
\hline \multirow{2}{*}{ Assets in Household ( $n=917$ ) } & Improved household & $654(71.3)$ & $323(73.4)$ & $331(69.4)$ & 0.189 \\
\hline & Poor household & $263(28.7)$ & $117(26.6)$ & $146(30.6)$ & \\
\hline \multicolumn{6}{|l|}{ Perceived social support: } \\
\hline \multirow{2}{*}{ Instrumental support ( $n=863$ ) } & Always/Often & $391(45.3)$ & $176(41.8)$ & $215(48.6)$ & .047 \\
\hline & Sometimes/Never & $472(54.7)$ & $245(58.2)$ & $227(51.4)$ & \\
\hline \multirow{2}{*}{ Informational support ( $\mathrm{n=908)}$} & Always/Often & $301(33.1)$ & $132(30.3)$ & $169(35.7)$ & .091 \\
\hline & Sometimes/Never & $607(66.9)$ & $303(69.7)$ & $304(64.3)$ & \\
\hline \multirow{2}{*}{ Emotional support $(\mathrm{n}=915)$} & Always/Often & $300(32.8)$ & $122(27.7)$ & $178(37.5)$ & .002 \\
\hline & Sometimes/Never & $615(67.2)$ & $318(72.3)$ & $297(62.5)$ & \\
\hline \multicolumn{6}{|l|}{ Partner characteristics: } \\
\hline \multirow{2}{*}{ Partner's education $(n=624)$} & Completed Primary school or Higher & $233(37.3)$ & $81(32.4)$ & $152(40.6)$ & .043 \\
\hline & Incomplete Primary school/No schooling & $391(62.7)$ & $169(67.6)$ & $222(59.4)$ & \\
\hline \multirow{2}{*}{ Partner employment status $(n=611)$} & Employed & $105(17.2)$ & $19(7.7)$ & $86(23.7)$ & .000 \\
\hline & Not employed & $506(82.8)$ & $229(92.3)$ & $277(76.3)$ & \\
\hline \multicolumn{6}{|c|}{ Suicidal behaviour (ideation, plan and/or attempt): } \\
\hline \multirow{2}{*}{ Suicidal behaviour $(\mathrm{n}=915)$} & Yes & $146(16.0)$ & $42(9.6)$ & $104(21.8)$ & .000 \\
\hline & No & $769(84.0)$ & $396(90.4)$ & $373(78.2)$ & \\
\hline
\end{tabular}

$\mathrm{X}-2$ test and Fisher's exact test $P$-values for differences between men and women in population. $\mathrm{n}=917$ 
Table 2. Descriptive statistics of clinical factors classified/presented by sex*

\begin{tabular}{|c|c|c|c|c|c|}
\hline & & Total (N=917), n (\%) & Men (N=440), n (\%) & Women (N=477), n (\%) & $P$-value \\
\hline \multirow{2}{*}{ Major depressive episode (past 2 weeks) $(\mathrm{n}=915)$} & Without MDE & $736(80.4)$ & $386(87.9)$ & $350(73.5)$ & .000 \\
\hline & With MDE & $179(19.6)$ & $53(12.1)$ & $126(26.5)$ & \\
\hline \multirow{4}{*}{ Physical pain (experienced almost daily) (n=902) } & 0 & $634(70.3)$ & $368(84.6)$ & $266(57.0)$ & .000 \\
\hline & 1 symptom & $135(15.0)$ & $57(13.1)$ & $78(16.7)$ & \\
\hline & 2 symptoms & $61(6.8)$ & $4(0.9)$ & $57(12.2)$ & \\
\hline & $\geq 3$ symptoms & $72(8.0)$ & $6(1.4)$ & $66(14.1)$ & \\
\hline \multirow{2}{*}{ Perceived overall health $(n=917)$} & Excellent/good/moderate & $639(69.7)$ & $327(74.3)$ & $312(65.4)$ & .003 \\
\hline & Poor/very poor & $278(30.3)$ & $113(25.7)$ & $165(34.6)$ & \\
\hline
\end{tabular}

MDE - major depressive episode

" $\chi-2$ test and Fisher's exact test $P$-values for differences between men and women in population. $\mathrm{n}=917$. 
Table 3. Associations between clinical factors and suicidal behaviour in women*

\begin{tabular}{lccc}
\hline & $\mathrm{n}(\%)$ & Crude OR (95\% Cl) & Adjusted OR (95\% CI) \\
\hline Major depressive episode & $98(27.7)$ & $6.70(4.17 ; 10.76)$ & $6.61(4.03 ; 10.84)$ \\
Age (20 as ref) & & $0.96(0.92 ; 1.01)$ & $0.98(0.93 ; 1.04)$ \\
Not married & & $1.62(1.02 ; 2.57)$ & $1.68(0.99 ; 2.85)$ \\
Poor household & & $1.41(0.89 ; 2.23)$ & $0.97(0.58 ; 1.63)$ \\
Poor emotional support & $188(46.1)$ & $1.74(1.08 ; 2.80)$ & $1.37(0.82 ; 2.32)$ \\
Physical pain almost daily & & $1.76(1.13 ; 2.73)$ & $1.80(1.15 ; 2.84)$ \\
Age (20 as ref) & & $0.97(0.92 ; 1.02)$ \\
Not married & & & $1.51(0.91 ; 2.50)$ \\
Poor household & & $1.31(0.81 ; 2.12)$ \\
Poor emotional support & & & $1.72(1.05 ; 2.81)$ \\
Poor perceived overall health & $126(35.5)$ & & $3.08(1.89 ; 5.00)$ \\
Age (20 as ref) & & $2.98(1.90 ; 4.65)$ & $0.95(0.90 ; 1.00)$ \\
Not married & & & $1.43(0.87 ; 2.37)$ \\
Poor household & & & $0.99(0.60 ; 1.63)$ \\
Poor emotional support & & $1.48(0.89 ; 2.44)$ \\
\hline
\end{tabular}

OR - odds ratio, $\mathrm{CI}$ - confidence interval

*Adjusted odds ratios with $95 \%$ CI. $n=477$ women

Table 4. Associations between clinical factors and suicidal behaviour in men*

\begin{tabular}{lccc}
\hline & $\mathrm{n}(\%)$ & Crude OR (95\% Cl) & Adjusted OR (95\% Cl) \\
\hline Major depressive episode & $34(13.8)$ & $6.80(3.36 ; 13.76$ & $4.75(1.72 ; 13.12)$ \\
Age (20 as ref) & & $0.96(0.89 ; 1.04)$ & $0.92(0.81 ; 1.04)$ \\
Poor household & & $1.80(0.93 ; 3.49)$ & $1.64(0.57 ; 4.70)$ \\
Partner not employed & & $0.28(0.08 ; 0.95)$ & $0.34(0.06 ; 0.89$ \\
Physical pain symptoms almost daily & $1.62(0.74 ; 3.57)$ & \\
Poor perceived overall health & & $1.74(0.89 ; 3.40)$ & \\
\hline
\end{tabular}

OR - odds ratio, $\mathrm{CI}$ - confidence interval

*Crude and Adjusted odds ratios with 95\% CI. n= 440 men.

versus $1.4 \%$ ) in the one month preceding the survey. Most studies report a similar pattern, with women having higher rates of suicidal behaviour (nonfatal) compared to men.6,29,41 A possible explanation for this difference may be due to women's overall life circumstances with less decision-making capacity than men, lower socioeconomic status and at risk of exposure to intimate partner violence (IPV). ${ }^{42-46}$ For example, Umubyeyi reported that IPV was significantly associated with several common mental disorders in women. ${ }^{42}$ In addition, the genocide against the Tutsi in 1994, still contributes to high rates of mental disorders in the population. ${ }^{18,42}$ Although not every person with suicidal thoughts acts upon it, a significant proportion of those progress to having a plan and others to attempting suicide. Kessler and colleagues ${ }^{31}$ reported that the majority (60\%) of planned attempts happen within one year of onset of suicidal ideation. This is an important indication that with adequate help, this progression could be halted. Although few people seek help for suicidal behaviour, ${ }^{2}$ a significant proportion of people with suicidal behaviour visit health care facilities for other problems. ${ }^{2}$ Therefore, there is an oppor- tunity to identify those at risk of suicidal behaviour or who may (possibly) progress to suicide completion.

\section{METHODOLOGICAL CONSIDERATIONS}

There is need for cautious interpretation of these results due to the cross-sectional nature of the study, whereby causality conclusions cannot be made as no temporal relationship is shown. However, the aim of this study is not to show causality but rather to identify correlates or cues that can be used to identify persons with or at risk of suicidal behaviour. In addition, due to the stigma associated with mental health issues in this context, ${ }^{17}$ there is a risk of MDE and suicidal behaviour to be underreported.

Importantly, the validity and accuracy of the data collected is high since participants were selected using a random sampling technique with almost full participation. Interviews were conducted by trained psychologists using validated instruments, and respondents were interviewed by young data collectors of the same sex as the participant, further enabling the discussion of sensitive information. Furthermore, the demographic and socioeconomic charac- 
teristics of this sample were similar (apart from employment status) to the findings of the Rwanda demographic health survey $2014-2015,{ }^{47}$ therefore, these findings can possibly be generalized to the population of young adults aged 20-35 years in Rwanda.

\section{IMPLICATIONS FOR POLICY AND FUTURE RESEARCH}

The prevention of suicide hinges upon the early identification of persons at risk. However, the mental health care system in Rwanda is faced with several challenges, notably few trained mental health professionals. ${ }^{10}$ Mental health nurses and general practice nurses form the backbone of mental health care as psychiatrists are few in the country and mainly based in the capital Kigali. ${ }^{48,49}$ Importantly, this was acknowledged in Rwanda's mental health policy $2011,{ }^{10}$ which advocated for training of more mental health professionals, working with community health workers and incorporating mental health care under insurance schemes. ${ }^{10}$ Therefore, community health workers, who are trusted persons in the community and regularly interface with the people ${ }^{17}$ can utilise the easy to administer selfrated health screening form to identify and refer or escort vulnerable persons to trained professionals at health centres. At health centres, patients should be assessed for depression and/or persistent physical pain symptoms and consequently, sufferers sensitively asked about suicidal behaviour. ${ }^{50}$ Existing research indicates that asking about suicidal behaviour in high risk populations does not increase the risk of suicide. ${ }^{51,52}$ Therefore, general practice nurses and community health workers can be trained to identify persons at risk and trained to ask about sensitive issues. An example of an evidence-based suicide prevention training module used in other countries is the Question, Persuade, Refer (QPR), ${ }^{53,54}$ which can be adapted and tested for the Rwandan context.

\section{CONCLUSIONS}

Suicidal behaviour (suicide ideation, plan, and/or attempt) is prevalent in young women and men in Rwanda, with rates twice as high in women compared to men. This study re- ports that major depressive episode, physical pain experienced almost daily, and poorly perceived overall health are statistically significant correlates of suicidal behaviour in women, while major depressive episode is a significant correlate of suicidal behaviour in men. These findings are to inform suicide prevention policy and practice in Rwanda.

\section{ACKNOWLEDGEMENTS}

We would like to thank the people of the Southern province of Rwanda who accepted to take part in the RwVMHBC study project.

\section{COPYRIGHT}

The MINI was reproduced with the permission of copyright holder, (c) Copyright 1994-2010 Sheenan DV \& Lecrubier Y.

\section{FUNDING}

Main study project conducted in 2011/2012 was funded by a grant from the Swedish International Development Cooperation Agency, SIDA. No role in data analysis and drafting of this manuscript.

\section{COMPETING INTERESTS}

The authors completed the Unified Competing Interest form at http://www.icmje.org/coi_disclosure.pdf (available upon request from the corresponding author) and declare no conflicts of interest.

\section{CORRESPONDENCE TO:}

Joseph Muwonge Junior

Kyndelsmässogränd 17

12637 Hägersten

Sweden

joeymuwonge@gmail.com 


\section{REFERENCES}

1. WHO. Depression and Other Common Mental Disorders: Global Health Estimates. World Health Organization; 2017.

2. WHO. Preventing Suicide: A Global Imperative. World Health Organization; 2014. http://www.who.in t/iris/handle/10665/131056

3. WHO. Global Health Observatory data repository: Suicide rate estimates, age-standardized Estimates by country in 2016. Published online 2018. Accessed December 3, 2018. http://apps.who.int/gho/data/vie w.main.MHSUICIDEASDRv?lang=en

4. WHO. Mental health-Suicide Data. Accessed February 7, 2018. http://www.who.int/mental health/ prevention/suicide/suicideprevent/en/

5. Oppong Asante K, Kugbey N, Osafo J, Quarshie ENB, Sarfo JO. The prevalence and correlates of suicidal behaviours (ideation, plan and attempt) among adolescents in senior high schools in Ghana. SSM Popul Health. 2017;3:427-434. doi:10.1016/j.ssm ph.2017.05.005

6. Adewuya AO, Ola BA, Coker OA, et al. Prevalence and associated factors for suicidal ideation in the Lagos State Mental Health Survey, Nigeria. BJPsych Open. 2016;2(6):385-389. doi:10.1192/bjpo.bp.116.00 $\underline{4333}$

7. Brenes GA. Anxiety, depression, and quality of life in primary care patients. Prim Care Companion J Clin Psychiatry. 2007;9(6):437-443. doi:10.4088/pcc.v09n0 $\underline{606}$

8. United Nations. Sustainable Development Knowledge Platform-SUSTAINABLE DEVELOPMENT GOAL 3. Published 2017. Accessed May 11, 2018. http s://sustainabledevelopment.un.org/sdg3

9. World Health Organization. Mental Health Action Plan 2013-2020. WHO; 2013.

10. Republic of Rwanda. National Mental Health Policy in Rwanda. Ministry of Health; 2011. Accessed February 11, 2018. http://www.moh.gov.rw/fileadmin/ templates/Docs/Posted-National-Mental-health-Polic y-1.pdf

11. Targum SD, Friedman F, Pacheco MN. Assessment of Suicidal behavior in the Emergency Department. Innov Clin Neurosci. 2014;11:194-200.

12. Roy A. Risk factors for suicide in psychiatric patients. Arch Gen Psychiatry. 1982;39(9):1089-1095. doi:10.1001/archpsyc.1982.04290090071014
13. Institute for Health Metrics and Evaluation. Rwanda (Country Profile). Published 2018. Accessed May 4, 2018. http://www.healthdata.org/rwanda

14. Republic of Rwanda. Health Sector Policy 2015. Ministry of Health. Accessed May 4, 2018. https://mo h.gov.rw/index.php?id=510

15. Ait Mohand A, Kayiteshonga Y. The set-up of a national mental health program in Rwanda. 9th European Congress on Tropcial Medicine and International Health 2015 ECTMIH 15, At Basel, Switzerland, 6 - 10 September 2015. Published online 2015.

16. DeSalvo KB, Bloser N, Reynolds K, He J, Muntner P. Mortality Prediction with a Single General SelfRated Health Question: A Meta-Analysis. J Gen Intern Med. 2006;21(3):267-275. doi:10.1111/j.1525-1497.20 $\underline{05.00291 . x}$

17. Umubyeyi A, Mogren I, Ntaganira J, Krantz G. Help-seeking behaviours, barriers to care and selfefficacy for seeking mental health care: a populationbased study in Rwanda. Soc Psychiatry Psychiatr Epidemiol. 2016;51(1):81-92. doi:10.1007/s00127-01 5-1130-2

18. Rugema L, Mogren I, Ntaganira J, Krantz G. Traumatic episodes and mental health effects in young men and women in Rwanda, 17 years after the genocide. BMJ Open. 2015;5(6):e006778. doi:10.1136/ bmiopen-2014-006778

19. Rugema L, Mogren I, Ntaganira J, Gunilla K. Traumatic episodes experienced during the genocide period in Rwanda influence life circumstances in young men and women 17 years later. BMC Public Health. 2013;13:1235. doi:10.1186/1471-2458-13-123 $\underline{5}$

20. NISR. Population size and Population characteristics. Published online 2018. Accessed March 12, 2019. http://www.statistics.gov.rw/statistic al-publications/subject/population-size-and-populati on-characteristics

21. National Institute of Statistics of Rwanda (NISR), Ministry of Finance and Economic Planning (MINECOFIN) [Rwanda], Rwanda Fourth Population and Housing Census. Thematic Report: Population size, structure and distribution. Supplementary materials- Table A 4 Resident population by sex, age and area of residence (counts). Published online 2012. 
22. Munyandamutsa N, Mahoro Nkubamugisha $P$, Gex-Fabry M, Eytan A. Mental and physical health in Rwanda 14 years after the genocide. Soc Psychiatry Psychiatr Epidemiol. 2012;47(11):1753-1761. doi:10.10 07/s00127-012-0494-9

23. Bolton P, Neugebauer R, Ndogoni L. Prevalence of depression in rural Rwanda based on symptom and functional criteria. J Nerv Ment Dis. 2002;190(9):631-637. doi:10.1097/00005053-2002090 00-00009

24. Sheehan DV, Lecrubier Y, Sheehan KH, Amorim P, Janavs J, Weiller E. The Mini-International Neuropsychiatric Interview (M.I.N.I.): the development and validation of a structured diagnostic psychiatric interview for DSM-IV and ICD-10. J Clin Psychiatry. 1998;59(Suppl 20):22-33, quiz 4-57.

25. Roaldset JO, Linaker OM, Bjørkly S. Predictive Validity of the MINI Suicidal Scale for Self-Harm in acute psychiatry: A prospective study of the first year after discharge. Arch Suicide Res. 2012;16(4):287-302. doi:10.1080/13811118.2013.722052

26. NISR, Ministry of Health (MOH), ICF International. Rwanda Demographic and Health Survey 2010. NISR, MOH, and ICF International; 2012. Accessed March 22, 2018. https://dhsprogram.com/pu bs/pdf/FR259/FR259.pdf

27. Dong Y, Peng CYJ. Principled missing data methods for researchers. Springerplus. 2013;2:222. do i: $10.1186 / 2193-1801-2-222$

28. Kwak SK, Kim JH. Statistical data preparation: management of missing values and outliers. Korean $J$ Anesthesiol. 2017;70(4):407-411. doi:10.4097/kjae.201 7.70.4.407

29. Bernal M, Haro JM, Bernert S, et al. Risk factors for suicidality in Europe: Results from the ESEMED study. J Affect Disord. 2007;101(1-3):27-34. doi:10.101 6/j.jad.2006.09.018

30. Sartorius N. The economic and social burden of depression. J Clin Psychiatry. 2001;62(Suppl 15):8-11.

31. Kessler RC, Borges G, Walters EE. Prevalence of and risk factors for lifetime suicide attempts in the national comorbidity survey. Arch Gen Psychiatry. 1999;56(7):617-626. doi:10.1001/archpsyc.56.7.617

32. Joiner TE, Van Orden KA, Witte TK, et al. Main predictions of the interpersonal-psychological theory of suicidal behavior: Empirical tests in two samples of young adults. J Abnorm Psychol. 2009;118(3):634-646. doi:10.1037/a0016500
33. Rukundo GZ, Kinyanda E, Mishara B. Clinical correlates of suicidality among individuals with HIV infection and AIDS disease in Mbarara, Uganda. Afr J AIDS Res. 2016;15(3):227-232. doi:10.2989/1608590 6.2016 .1182035

34. Tang NKY, Crane C. Suicidality in chronic pain: a review of the prevalence, risk factors and psychological links. Psychol Med. 2006;36(5):575-586. doi:10.1017/s0033291705006859

35. McEwen BS. Protective and damaging effects of stress mediators. N Engl J Med. 1998;338(3):171-179. doi:10.1056/neim199801153380307

36. Dillon G, Hussain R, Loxton D, Rahman S. Mental and Physical health and intimate partner violence against women: A review of the literature. Int J Family Med. 2013;2013:313909. doi:10.1155/2013/313909

37. Umubyeyi A, Mogren I, Ntaganira J, Krantz G. Women are considerably more exposed to intimate partner violence than men in Rwanda: results from a population-based, cross-sectional study. $B M C$ Women's Health. 2014;14:99. doi:10.1186/1472-687 $\underline{\text { 4-14-99 }}$

38. Goodwin RD, Marusic A. Perception of health, suicidal ideation, and suicide attempt among adults in the community. Crisis. 2011;32(6):346-351. doi:1 $\underline{0.1027 / 0227-5910 / \mathrm{a} 000104}$

39. Krause NM, Jay GM. What do global self-rated health items measure? Med Care. 1994;32(9):930-942. doi:10.1097/00005650-199409000-00004

40. Goodwin R, Olfson M. Self-perception of poor health and suicidal ideation in medical patients. Psychol Med. 2002;32(7):1293-1299. doi:10.1017/s003 $\underline{3291702006323}$

41. Li H, Luo X, Ke X, et al. Major depressive disorder and suicide risk among adult outpatients at several general hospitals in a Chinese Han population. PLoS One. 2017;12(10):e0186143. doi:10.1371/journal.pon e.0186143

42. Umubyeyi A, Mogren I, Ntaganira J, Krantz G. Intimate partner violence and its contribution to mental disorders in men and women in the post genocide Rwanda: findings from a population based study. BMC Psychiatry. 2014;14:315. doi:10.1186/s128 88-014-0315-7

43. Verduin F, Engelhard EAN, Rutayisire T, Stronks $\mathrm{K}$, Scholte WF. Intimate partner violence in Rwanda: the mental health of victims and perpetrators. $J$ Interpers Violence. 2013;28(9):1839-1858. doi:10.117 $\underline{7 / 0886260512469106}$ 
44. Braaf R, Meyering I. The Gender Debate in Domestic Violence: The Role of Data. Australian Domestic and Family Violence Clearinghouse. The University of New South Wales; 2013.

45. Jennie W. Women's Mental Health Taking Inequality into Account (Chapter 8). In: Tew J, ed. Social Perspectives in Mental Health: Developing Social Models to Understand and Work with Mental Distress. Jessica Kingsley Publishers; 2004:151-167.

46. Devries K, Watts C, Yoshihama M, et al. Violence against women is strongly associated with suicide attempts: Evidence from the WHO multi-country study on women's health and domestic violence against women. Soc Sci Med. 2011;73:79-86. doi:10.10 16/i.socscimed.2011.05.006

47. NISR, Ministry of Health (MOH) [Rwanda], ICF International. Rwanda Demographic and Health Survey 2014-15. National Institute of Statistics of Rwanda (NISR), MOH, and ICF International; 2015.

48. Rugema L, Krantz G, Mogren I, Ntaganira J, Persson M. "A constant struggle to receive mental health care": health care professionals' acquired experience of barriers to mental health care services in Rwanda. BMC Psychiatry. 2015;15:314. doi:10.1186/ s12888-015-0699-z
49. World Health Organization. Rwanda Mental Health Atlas Country Profile. Department of Mental Health and Substance Abuse, World Health Organization; 2011. Accessed February 20, 2018. http://www.who.in $\mathrm{t}$ /mental_health/evidence/atlas/profiles/rwa_mh_profi le.pdf?ua $=1$

50. Busch KA, Fawcett J, Jacobs DG. Clinical correlates of inpatient suicide. J Clin Psychiatry. 2003;64:14-19. doi:10.4088/icp.v64n0105

51. Dazzi T, Gribble R, Wessely S, Fear NT. Does asking about suicide and related behaviours induce suicidal ideation? What is the evidence? Psychol Med. 2014;44(16):3361-3363. doi:10.1017/s0033291714001 $\underline{299}$

52. Mathias CW, Michael Furr R, Sheftall AH, HillKapturczak N, Crum P, Dougherty DM. What's the harm in asking about suicidal ideation? Suicide Life Threat Behav. 2012;42(3):341-351. doi:10.1111/j.194 3-278x.2012.0095.x

53. Question, Persuade, and Refer. Accessed February 10, 2019. https://qprinstitute.com/about-qpr

54. Collings S, Jenkin G, Stanley J, McKenzie S, Hatcher S. Preventing suicidal behaviours with a multilevel intervention: a cluster randomised controlled trial. BMC Public Health. 2018;18:140. do i: 10.1186/s12889-018-5032-6 